\title{
Pemetaan Distribusi Gas Polutan Menggunakan Quadcopter Berbasis Autonomous Waypoint Navigation
}

\author{
Irfan Fachrudin Priyanta, Muhammad Rivai, Rudy Dikairono \\ Jurusan Teknik Elektro, Fakultas Teknologi Industri, Institut Teknologi Sepuluh Nopember (ITS) \\ Jl. Arief Rahman Hakim, Surabaya 60111 Indonesia \\ e-mail: muhammad_rivai@ee.its.ac.id,rudydikairono@ee.its.ac.id
}

\begin{abstract}
Abstrak-Pencemaran udara adalah suatu kondisi dimana kualitas udara menjadi rusak dan terkontaminasi oleh zat-zat, baik yang tidak berbahaya maupun berbahaya bagi makhlup hidup. Seiring dengan perkembangan dan pembangunan industri di Indonesia, akan berdampak pada meningkatnya tingkat pencemaran udara. Sistem monitoring emisi gas polutan industri secara umum dilakukan dengan cara manual menggunakan sensor gas pada titik-titik tertentu. Hal ini memakan waktu dan biaya cukup banyak. Quadcopter merupakan salah satu jenis Unmanned Aerial Vehicle (UAV) yang mampu bergerak secara otomatis sesuai dengan sistem tracking waypoint. Sistem tracking waypoint merupakan sistem navigasi berdasarkan posisi Global Positioning System (GPS) dan kompas, sehingga quadcopter dapat berjalan secara otomatis. Implementasi sensor gas semikonduktor dapat menunjang quadcopter untuk mengukur kadar gas di udara, sehingga dapat diaplikasikan sebagai alat monitoring secara otomatis. Data posisi GPS quadcopter dapat diakses secara langsung pada google maps di software mission planner. Kadar gas polutan disimpan pada web server raspberry pi 2 dan mampu diakses secara online. Hasil pemetaan kadar gas ditampilkan dalam 3D analyzer google earth.
\end{abstract}

Kata Kunci-Pencemaran Udara, Quadcopter, Sensor Gas Semikonduktor, Waypoint.

\section{PENDAHULUAN}

$\mathrm{P}$ ENCEMARAN udara menurut Peraturan Pemerintah Republik Indonesia No. 41 Tahun 1999 mengenai Pengendalian Pencemaran Udara, adalah masuknya atau dimasukannya zat, energi, dan/atau komponen lain ke dalam udara ambien oleh kegiatan manusia sehingga mutu udara ambien turun sampai ke tingkat tertentu yang menyebabkan udara ambien tidak memenuhi fungsinya. Kota Surabaya sebagai kota metropolitan di Indonesia menyumbang berbagai macam pemcemaran udara. Pencemaran udara di Kota Surabaya, $70 \%$ diakibatkan oleh transportasi, sisanya disebabkan oleh industri dan limbah (persampahan).

Sektor industri merupakan penyumbang pencemaran terutama yang berhubungan dengan proses kegiatan industri tersebut. Emisi industri turut menyumbang terhadap penurunan kualitas udara karena belum semua industri memiliki alat pengendali pencemar udara yang memadai. Industri-industri besar yang menggunakan bahan bakar fosil banyak menghasilkan gas buang yang dapat menyebabkan pencemaran udara [1].
Aktivitas industri di Surabaya yang berkembang di sekitar Rungkut, Wonokromo, dan Gresik telah menunjukkan penurunan kualitas udara. Setiap pabrik selayaknya mengikuti Keputusan MENLH Nomor KEP-13/MENLH/03/1995 tentang Baku Mutu Emisi Sumber Tidak Bergerak. Dimana setiap pabrik wajib memenuhi baku mutu emisi udara menggunakan alat atau teknologi terbarukan. Sesuai dengan Keputusan MENLH tersebut, setiap industri wajib memiliki alat pengendali pencemar udara yang memadai. Beberapa pabrik telah memasang sensor gas sebagai alat monitoring pencemaran udara, namun sebagian besar masih melanggar aturan. Sehingga pemkot melakukan inspeksi ke setiap pabrik yang memakan biaya cukup besar dan waktu yang cukup lama.

Unmanned Aerial Vehicle (UAV) merupakan jenis pesawat tanpa awak yang berguna untuk melakukan sistem monitoring pada suatu wikayah. Vertical Take Off Landing (VTOL) merupakan salah satu jenis UAV yang menggunakan banyak baling-baling sebagai penggeraknya. Salah satu jenis VTOL adalah Quadcopter dimana kestabilan dalam melakukan pemantauan jarak jauh dan pengambilan data menjadi nilai positif UAV jenis VTOL. Quadcopter memiliki fitur Tracking Waypoint dimana Quadcopter mampu bergerak secara otomatis mengikuti panduan Waypoint GPS (Global Positioning System) yang dideklarasikan oleh user [2].

Penelitian ini dirancang untuk mengaplikasikan Quadcopter, dengan menggunakan STM32F4 untuk proses pembacaan sensor gas semikonduktor dan data GPS. Sistem ini diharapkan mampu menjadi solusi untuk pemetaan distribusi polutan gas pada kawasan industri di Kota Surabaya secara efisien dan mudah.

\section{TEORI PENUNJANG}

\section{A. Sensor Semikonduktor}

Sensor gas adalah sensor yang berfungsi untuk mengukur senyawa gas polutan yang ada di udara seperti karbon monoksida, hidrokarbon, nitrooksida, dan lain-lain. Sensor gas semikonduktor memiliki banyak jenis, yang dibedakan oleh sensitivitas sensor tersebut. Prinsip kerja dari sensor ini semakin tinggi kosentrasi gas maka resistansinya semakin rendah. Sensor gas semikonduktor terbentuk pada permukaan luar kristal, tegangan permukaan yang terbentuk akan menghambat laju aliran elektron. 


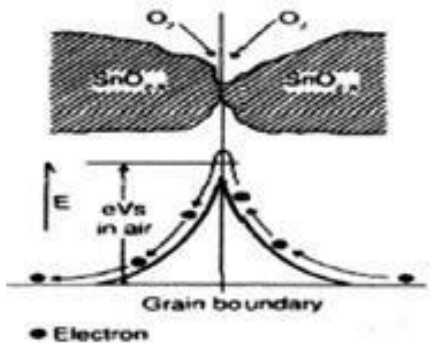

Gambar 1. Ilustrasi penyerapan $\mathrm{O}_{2}$ oleh sensor [3]
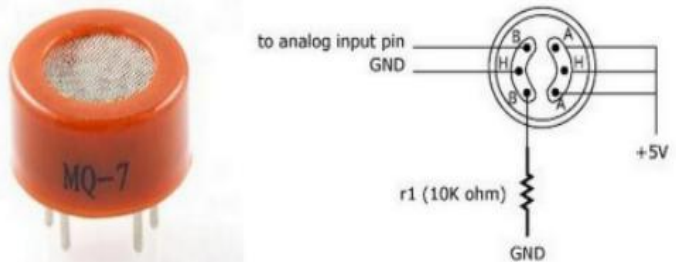

Gambar 2. Sensor Gas MQ-7

\section{B. Sensor Gas $M Q-7$}

Sensor gas MQ-7 merupakan sensor gas karbon monoksida (CO) yang berfungsi untuk mengetahui konsentrasi gas $\mathrm{CO}$. Keluaran yang dihasilkan oleh sensor ini adalah berupa sinyal analog. Seperti gambar 2, sensor ini terdapat nilai resistansi sensor (Rs) yang dapat berubah bila terkena gas dan juga sebuah pemanas yang digunakan sebagai pembersihan ruangan sensor dari kontaminasi udara luar. Output sensor dihubungkan ke analog digital converter (ADC), sehingga keluaran dapat ditampilkan dalam bentuk sinyal digital.

\section{Quadcopter}

Quadcopter adalah pengembangan dari helikopter yang hanya memiliki sebuah rotor, teknologi yang terdapat pada quadcopter ini mengunakan sinkronisasi antara keempat rotor yang dikonfigurasikan dalam bentuk frame plus (+). Quadcopter dapat melakukan take off dan landing secara vertikal sehingga biasa disebut sebagai VTOL (Vertical Take Off and Landing). Konfigurasi gerakan dari quadcopter ditunjukkan pada gambar 3. Dimana baling-baling depan dan belakang berputar dengan arah yang sama, serta baling-baling kanan dan kiri berputar dengan arah yang sama. Variasi kecepatan rotor, dapat mengubah gaya angkat dan menciptakan gerak. Dengan demikian, meningkatkan atau menurunkan kecepatan kempat baling-baling bersama-sama menghasilkan gerakan vertikal [4].

\section{Navigasi Pada Quadcopter}

Navigasi merupakan teknik untuk membaca kedudukan (posisi) dan arah benda terhadap kondisi di sekitarnya. Pada umumnya menemukan keduduan dan posisi dari benda dapat dilakukan dengan melihat beberapa penanda dengan sensor.

\section{- Global Positioning System (GPS)}

GPS Adalah navigasi berbasis sistem satelit yang menyediakan informasi lokasi dan waktu. Navigasi GPS terbentuk dari garis pandang empat satelit atau lebih. Navigasi GPS memiliki tingkat error \pm 5 meter terhadap posisi aktual, dan tidak bertambah sepanjang waktu. Konfigurasi pin GPS M8N ditunjukkan pada gambar 4.

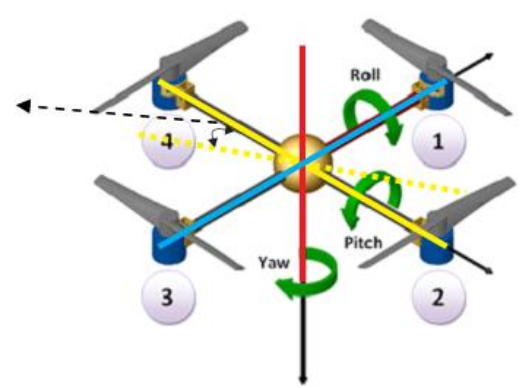

Gambar 3. Skema Gerakan Quadcopter

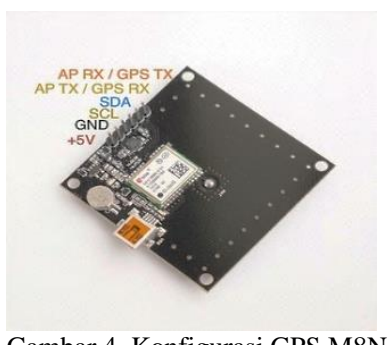

Gambar 4. Konfigurasi GPS M8N

- Sistem Inertial Measurement Unit ( IMU )

Inertial Measurement Unit (IMU) merupakan suatu unit dalam modul elektronik yang mengumpulkan data percepatan angular dan akselerasi linear, yang kemudian dikirim ke unit pemroses utama. Inertial Measurement Unit (IMU) adalah komponen utama dalam sistem GNC (Guidance, Navigation, and Control) yang berfungsi menangkap parameter-paramater sinyal yang dibutuhkan dalam sistem navigasi [5].

- PIXHAWK Flight Controller

Flight Controller (FC) merupakan otak atau komputer utama dari multirotor. Dalam sebuah FC terdapat beberapa hardware sensor seperti Accelerometer, Gyro, Magnetometer, GPS. Modul pixhawk memiliki beberapa pin untuk fungsi-fungsi yang berbeda seperti gambar 5. Pixhawk membaca seluruh data sensor dan memproses seluruhnya untk memerintahkan keempat motor untuk berputar sesuai dengan perintah dari FC [6].

\section{- Software Mission Planner}

Software mission planner digunakan untuk membuat waypoint pada quadcopter yang sudah terinstal APM/Pixhawk. Pada penelitian ini, software mission planner digunakan untuk memberikan titik-titik lokasi (waypoint) dimana quadcopter harus menyusurinya. Deklarasi waypoint ditunjukkan pada gambar 6.

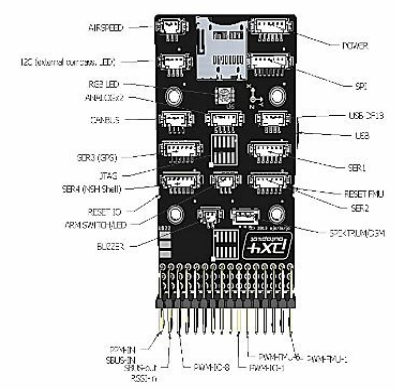

Gambar 5. Konfigurasi Pixhawk Flight Controller 


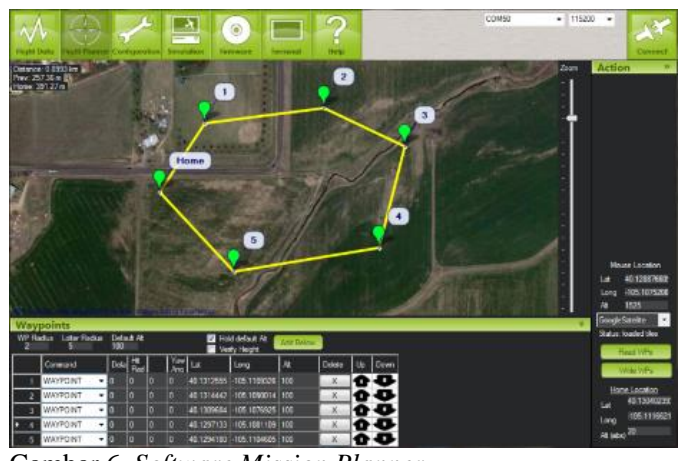

Gambar 6. Software Mission Planner

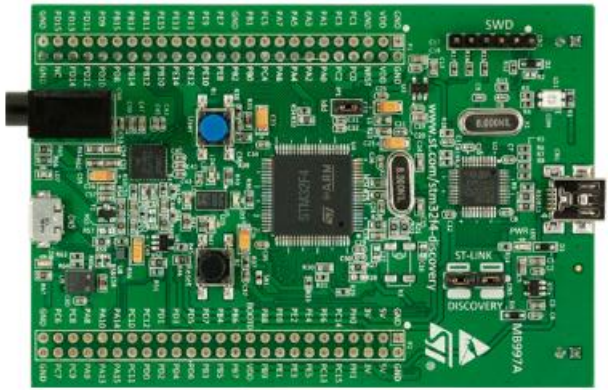

Gambar 7. STM32F4- Discovery

\section{E. STM $32 F 4$}

STM32F4 adalah produk dari ST Electronics yang memudahkan penggunanya untuk melakukan bebagai macam eksperimen elektronik. Mikrokontroller ARM STM32F407VG DISCOVERY adalah sebuah modul mikrokontroller yang dijadikan menjadi sebuah modul dengan tujuan untuk mempelajari fungsi-fungsi yang dimiliki oleh mikrokontroller ARM STM32F4 [7]. Modul STM32 yang digunakan ditunjukkan pada gambar 7 .

\section{F. Raspberry Pi 2}

Raspberry Pi adalah komputer papan tunggal (Single Board Circuit /SBC). Desain Raspberry Pi didasarkan seputar SoC (System-on-a-chip) Broadcom BCM2835, yang telah menanamkan prosesor ARM1176JZF-S dengan $700 \mathrm{MHz}$, VideoCore IV GPU, dan 256 Megabyte RAM (model B). Board raspberry yang digunakan ditunjukan pada gambar 8. Sistem operasi utama Raspberry Pi menggunakan Debian GNU/Linux dan bahasa pemrograman Python. Pada penelitian ini, raspberry pi digunakan sebagai data logger berupa web server.

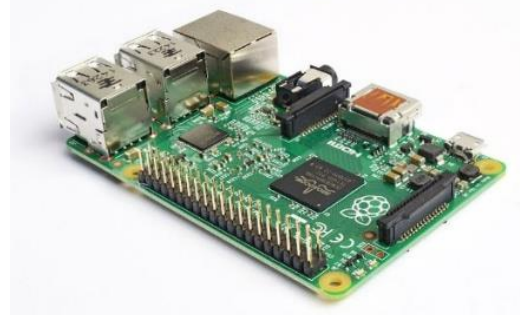

Gambar 8. Raspberry Pi 2 Model B

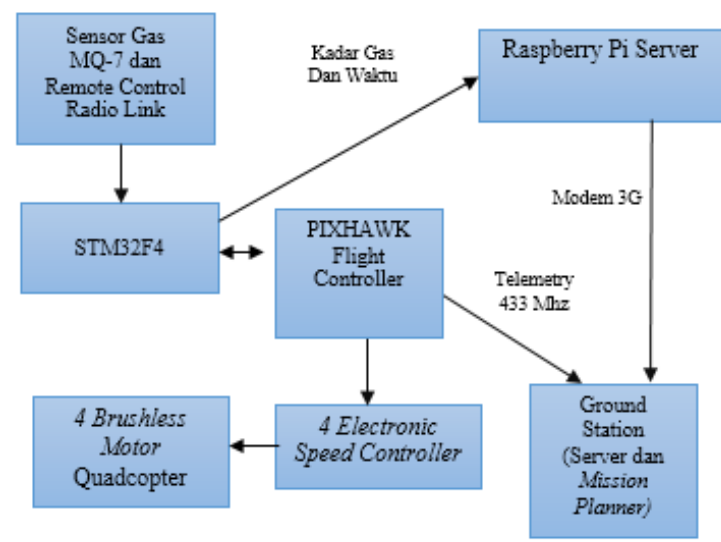

Gambar 9. Diagram Blok Sistem Quadcopter

\section{PERANCANGAN SISTEM}

\section{A. Diagram Blok Sistem}

Secara umum sistem ini terdiri dari perangkat keras dan perangkat lunak. Perangkat keras meliputi perancangan perangkat elektrik dan perangkat mekanik. Perangkat lunak meliputi program STM32F4, Raspberry Pi 2, kendali waypoint, dan kontrol Proposional Integral Derivatif (PID) menggunakan software mission planner. Sistem kerja dari quadcopter ditunjukkan pada gambar 9. Quadcopter mendeteksi dan menjangkau sumber gas dengan menggunakan sensor semikonduktor MQ-7 dengan metode waypoint. Lalu data kadar gas disajikan pada web server di raspberry pi 2 dan data lokasi GPS quadcopter pada software mission planner menggunakan telemetry $433 \mathrm{Mhz}$.

\section{B. Perancangan Perangkat Elektrik}

Perangkat elektrik meliputi power module distributor, power supply, rangkaian sensor, STM32F4, pixhawk, dan raspberry pi 2.

\section{- Rangkaian Sensor MQ-7}

Sensor MQ-7 merupakan salah satu sensor gas yang dapat mendeteksi udara CO (Karbon Monoksida) di udara. Agar didapatkan data tegangan output sensor, maka menggunakan modul rangkaian sensor MQ-7 seperti gambar 10.

\section{- STM32F4}

Fungsi dari STM32F4 ini untuk mengkonversi data analog menjadi digital dengan memanfaatkan ADC internal dan mengolahnya menjadi input untuk dikonversi pada sebuah algoritma agar menghasilkan data ppm (part per million). Algoritma konversi tersebut didapatkan dari hasil kalibrasi sensor gas MQ-7 dengan gas CO. Tegangan 5 volt dihasilkan oleh rangkaian buck converter. Sensor yang digunakan berjumlah satu sensor MQ-7. STM32F4 telah dilengkapi USART untuk proses pengiriman dan penerima data. Keluaran STM32F4 ini dikirim ke raspberry pi 2 dengan menggunakan port serial TX (transmitter) pada port A2 dan A3. 


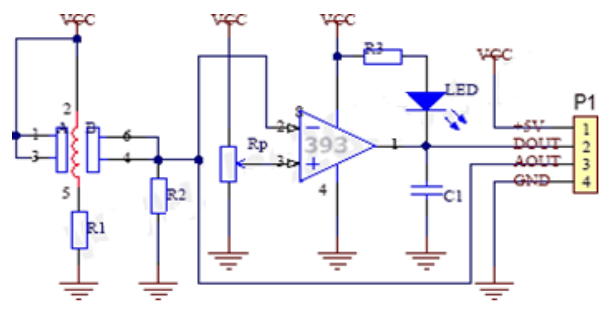

Gambar 10. Rangkaian Sensor MQ-7

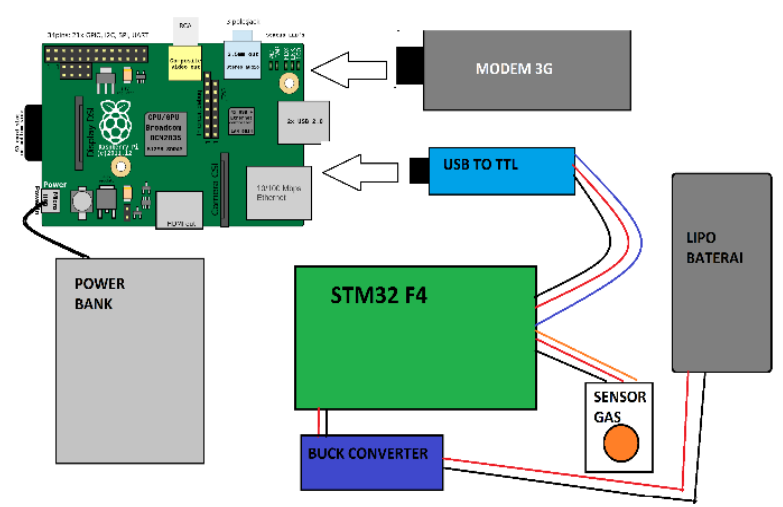

Gambar 11. Konfigurasi Raspberry Pi 2

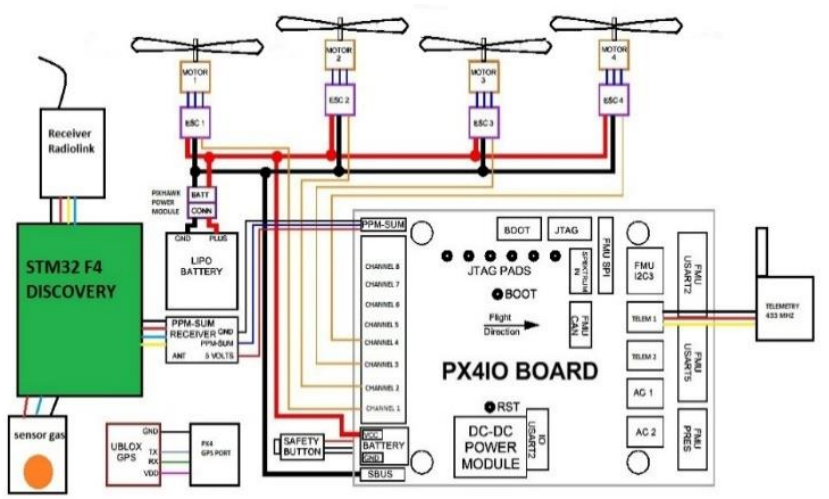

Gambar 12. Konfigurasi Pixhawk dengan semua perangkat quadcopter

\section{- $\quad$ Konfigurasi Sistem Elektrik Quadcopter}

Raspberry pi 2 berguna sebagai web server untuk menyajikan data kadar gas PPM dalam sebuah web socket. Konfigurasi sistem elektrik ditunjukkan gambar 11 dan 12. Raspberry pi 2 memiliki input tegangan sebesar 5 volt 1,8 A. Agar dapat memenuhi suplai tegangan, maka sebuah power bank 5000mah dipasang pada quadcopter. USB to TTL berisi data kadar gas dari STM32F4 dimasukkan pada port USB0. Modem untuk akses online ke web socket dipasang pada port USB3.

Pixhawk merupakan flight controller berbasis ARM STM32 yang dapat digunakan input-output hingga 8 channel. Dalam penelitian ini, pixhawk digunakan untuk menerima input dari STM32F4 lalu meneruskan data sinyal pwm ke output channel 1 hingga 4. Data GPS dan kompas disambungkan ke port GPS dan I2C. Telemetry $433 \mathrm{Mhz}$ diinputkan pada port telem1 yang berbasis USART. Port power merupakan output tegangan dari power module yang telah dikonversi menjadi 5 volt. Terdapat switch untuk safety sebelum melakukan arming ke quadcopter. Buzzer untuk indikator masing-masing perintah.

\section{Perancangan Mekanik Quadcopter}

Perancangan mekanik meliputi perhitungan beban quadcopter, desain awal frame quadcopter pada software auto cad (gambar 13) hingga realisasi mekanik quadcopter. Dalam desain awal quadcopter, rangka yang akan diterapkan menggunakan ukuran s700. Terdapat 4 brushless motor DC yang dipasang pada rangka. Perancangan ukuran total quadcopter pada penelitian ini adalah (panjang x lebar) 55x46 $\mathrm{cm}$.

\section{PENGUJIAN DAN ANALISIS SISTEM}

Pengujian sistem quadcopter dibagi menjadi beberapa tahap bagian, dimulai dari pengujian perangkat keras dan perangkat lunak. Gambar 14 merupakan quadcopter yang digunakan. Tujuan dari pengujian dari berbagai aspek dari perancangan ini untuk mendapatkan parameter atau evaluasi performa dari quadcopter.

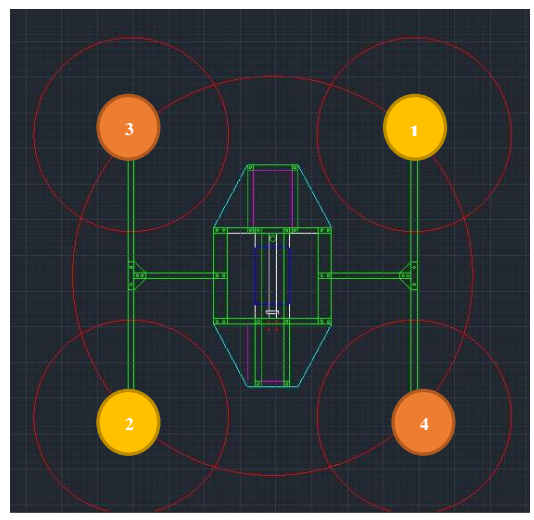

Keterangan :

1.Motor Brushless CCW

2.Motor Brushless CW

3.Motor Brushless CCW

4.Motor Brushless CW

Gambar 13. Desain Quadcopter pada Auto Cad

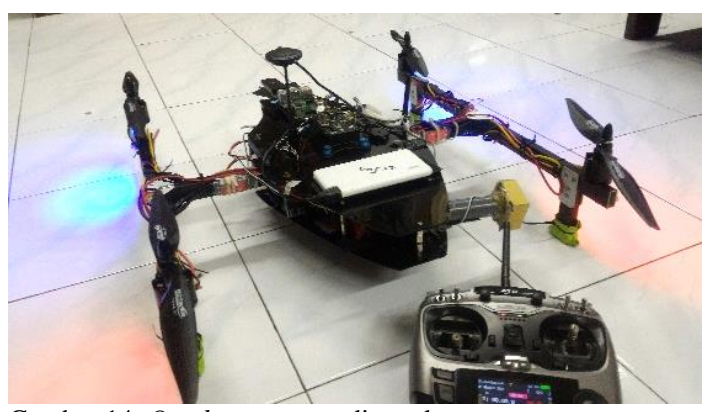

Gambar 14. Quadcopter yang diterapkan

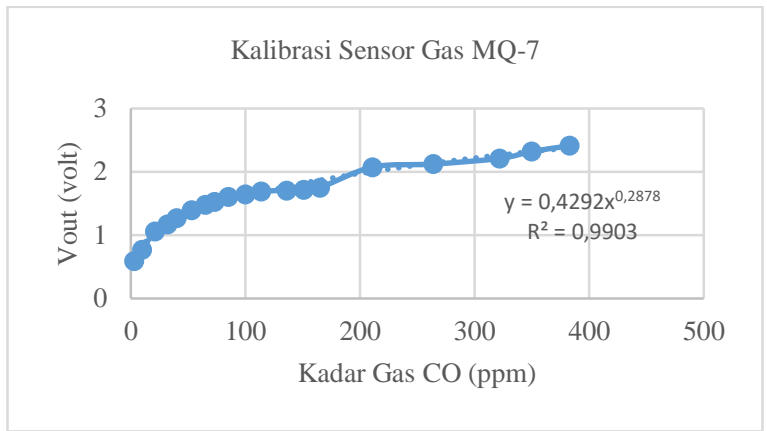

Gambar 15. Fungsi algoritma dari kalibrasi sensor gas MQ-7 
Tabel 2.

\begin{tabular}{cccc}
\multicolumn{4}{c}{ Perbandingan nilai sensor gas mq-7 dengan CO-meter } \\
\hline \hline No & CO-meter (ppm) & Sensor Gas (ppm) & Error $(\%)$ \\
\hline 1 & 3 & 3,02 & 0,67 \\
2 & 10 & 7,62 & 23,8 \\
3 & 12 & 12,27 & 2,25 \\
4 & 14 & 11,97 & 14,5 \\
5 & 21 & 22,98 & 9,43 \\
6 & 22 & 23,35 & 6,13 \\
7 & 24 & 26,71 & 11,29 \\
8 & 32 & 32,6 & 1,875 \\
9 & 53 & 59,48 & 12,22 \\
10 & 56 & 62,66 & 11,89 \\
\multicolumn{4}{c}{} \\
\hline \hline
\end{tabular}

\section{A. Pengujian Sensor Gas MQ-7}

Pada pengujian ini, sensor gas mq-7 dikalibrasi menggunakan gas karbon monoksida dan alat ukur CO-meter model 7701 az instrument. Hasil kalibrasi didapatkan fungsi algoritma untuk konversi tegangan ADC ke satuan part per million (PPM).

Fungsi algoritma didapatkan dari fungsi grafik dari microsoft excel dengan regresi (trendline) power. Pada gambar 15 didapatkan $\mathrm{y}=0,4292 \mathrm{x}^{-0,2878}$ dan akurasi antar data $\left(\mathrm{R}^{2}\right)$ sebesar 99,03\%. Fungsi algoritma tersebut dimasukkan ke dalam program STM32F4. Dari hasil kalibrasi sensor gas MQ-7 didapatkan hasil perbandingan pembacaan sensor gas MQ-7 dengan CO-meter seperti tabel 2.

\section{B. Pengujian Seluruh Sistem}

Pengujian seluruh sistem dilakukan dengan lengkap dimana keberhasilan pendeteksian gas dan quadcopter mampu melewati titik-titik waypoint. Pengujian dilakukan pada sebuah lapangan dengan ukuran 30x12 meter seperti gambar 16. Gas polutan berasal dari hasil pembakaran sampah pada titik-titik tertentu.

Pada pengujian berikut, nilai ketinggian (altitude) ditetapkan setinggi 4 meter. Pengujian dilakukan saat dan setelah sampah dibakar. Pembakaran sampah dilakukan pada jarak yang dijangkau oleh titik waypoint yang dideklarasikan pada gambar 17. Pembacaan sensor gas memanfaatkan aliran udara yang dihasilkan oleh hasil penyedotan propeller quadcopter lalu diteruskan menuju corong sensor gas MQ-7.

Pada tabel 3, didapatkan nilai dari longitude (busur), lattitude (lintang), dan altitude saat quadcopter melakukan misi waypoint. Dari hasil pengujian, quadcopter berhasil mengikuti semua titik waypoint.

Setelah pengujian terbang, maka data peta diolah menggunakan software mission planner dan google earth. Data kadar gas, diolah raspberry pi 2 menggunakan plotly web server, didapatkan hasil pada gambar 18. Sedangkan, data posisi digambarkan dalam 3D analyzer google earth, sehingga didapatkan hasil seperti gambar 19. Data PPM dan posisi quadcopter dipetakan pada google earth. Tabel 4 menunjukkan hasil dari pembacaan sensor gas pada tempat yang dilalui quadcopter.

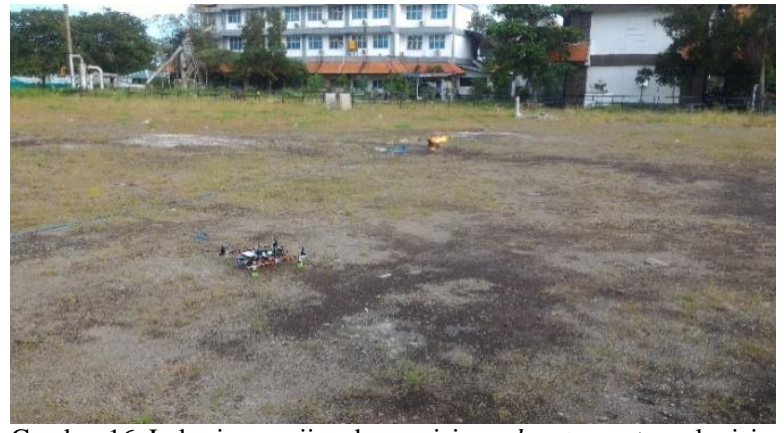

Gambar 16. Lokasi pengujian dan posisi quadcopter saat awal misi

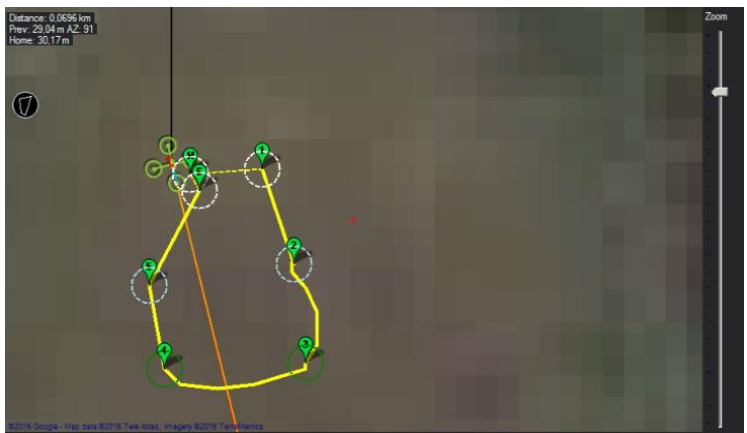

Gambar 17. Deklarasi waypoint dan tampilan google maps di mission planner

Tabel 3.

Nilai GPS Pengujian Waypoint

\begin{tabular}{lcccc}
\hline \hline No & Jenis Misi & Altitude & Latitude & Longitude \\
\hline 1 & Waypoint 1 & 4 & $-7,284336$ & 112,797474 \\
2 & Loiter(WP 2) & 4 & $-7,284431$ & 112,797518 \\
3 & Waypoint 3 & 4 & $-7,28454$ & 112,797529 \\
4 & Waypoint 4 & 4 & $-7,28455$ & 112,797365 \\
5 & Waypoint 5 & 4 & $-7,28445$ & 112,797341 \\
6 & Loiter & 4 & $-7,28435$ & 112,79741 \\
\hline \hline
\end{tabular}

Tabel 4

Data kadar gas PPM

\begin{tabular}{ccc}
\hline \multicolumn{3}{c}{ Data kadar gas PPM } \\
\hline No & Waktu & Kadar Gas (PPM) \\
\hline 1 & $16: 29: 46.960723$ & 3.5 \\
2 & $16: 29: 46.960723$ & 3.58 \\
3 & $16: 29: 47.844330$ & 4.04 \\
4 & $16: 29: 51.244025$ & 3.86 \\
5 & $16: 29: 54.272578$ & 3.65 \\
6 & $16: 29: 56.416153$ & 3.53 \\
7 & $16: 30: 04.103290$ & 3.54 \\
8 & $16: 30: 06.245508$ & 3.58 \\
9 & $16: 30: 10.531799$ & 3.4 \\
10 & $16: 30: 13.559195$ & 3.3 \\
11 & $16: 30: 14.816906$ & 3.52 \\
12 & $16: 30: 24.272735$ & 3.3 \\
13 & $16: 30: 25.530374$ & 3.52 \\
14 & $16: 30: 38.388819$ &
\end{tabular}




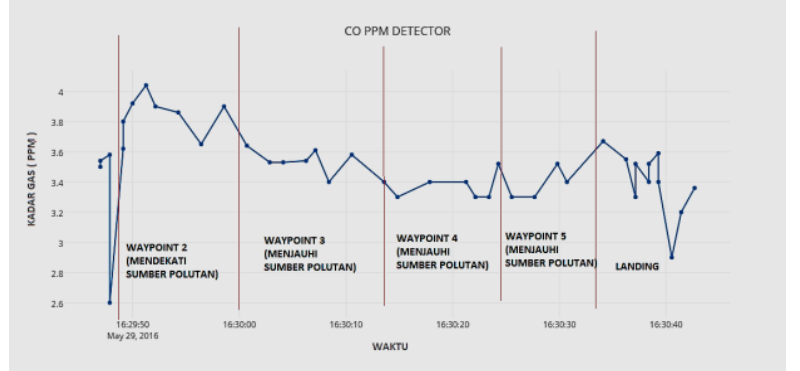

Gambar 18. Hasil kadar gas CO pada plotly web server

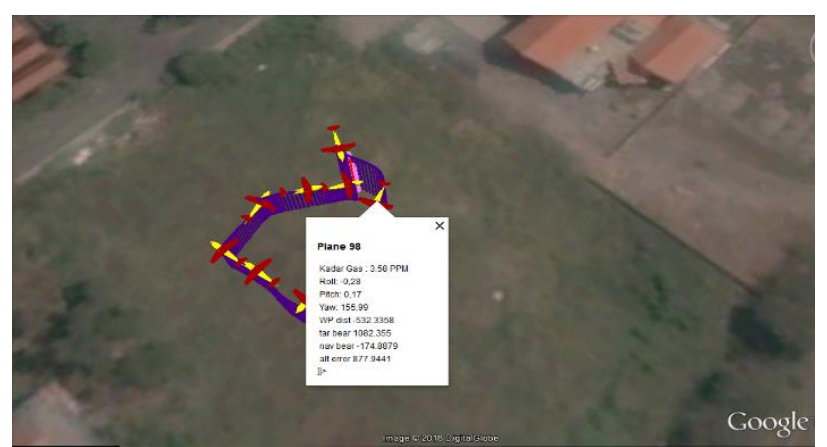

Gambar 19. Hasil 3D analyzer di google earth dan hasil pemetaan kadar gas

Tabel 5

Data kadar gas PPM saat di ground

\begin{tabular}{cccc}
\hline \hline No & CO-meter (ppm) & Sensor Gas $(\mathrm{ppm})$ & Selisih ppm \\
\hline 1 & 0 & 0,6 & 0,6 \\
2 & 0 & 0,8 & 0,8 \\
3 & 0 & 1,3 & 1,3 \\
4 & 1 & 1,5 & 0,5 \\
5 & 4 & 1,4 & 2,6 \\
6 & 4 & 1,7 & 2,3 \\
7 & 2 & 1,3 & 0,7 \\
8 & 2 & 1,4 & 0,6 \\
9 & 0 & 1,4 & 1,4 \\
10 & 0 & 1,3 & 1,3 \\
\multicolumn{4}{l}{} \\
\hline \hline
\end{tabular}

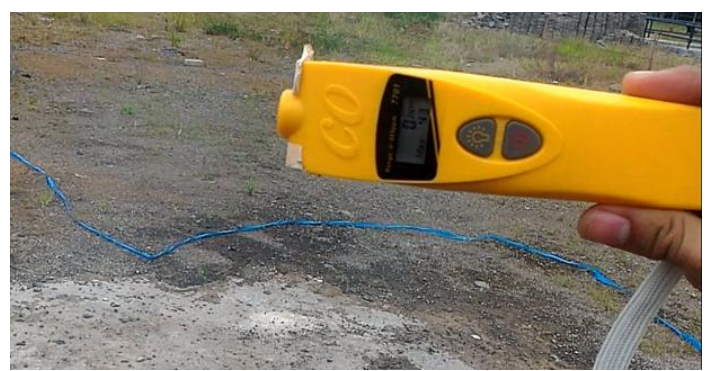

(a)

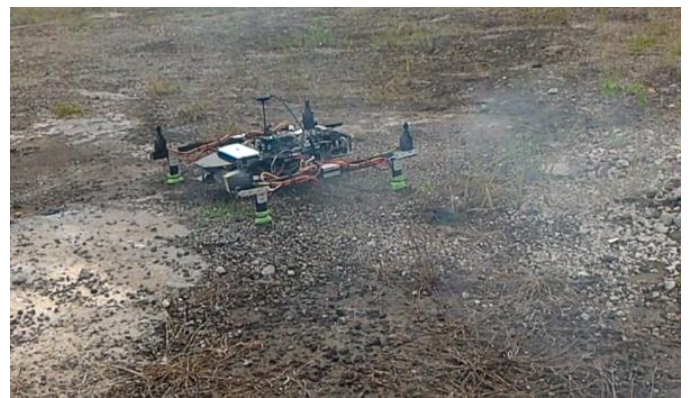

(b)

Gambar 19. Pengujian saat quadcopter di ground, (a) CO-meter yang terukur, (b) quadcopter saat throttle awal dan menyedot gas
Agar mendapatkan hasil yang diharapkan, sistem quadcopter diuji saat berada di posisi ground seperti gambar 19a dan 19b. Dimana quadcopter dan CO-meter diletakkan di dekat sumber polutan. Sehingga diperoleh data perbandingan selisih pengukuran antara sensor gas MQ-7 dengan CO-meter. Tabel 5 menunjukkan error selisih rata-rata dari 10 sampel sebesar 1,11 ppm. Dapat disimpulkan bahwa terdapat selisih error pembacaan sensor gas MQ-7 dengan CO-meter di ground sebesar $\pm 0,5-3 \mathrm{ppm}$.

\section{KESIMPULAN}

Dari perancangan, realisasi, dan pengujian alat pada penelitian ini dapat disimpulkan bahwa metode regresi linier dengan fungsi power dapat digunakan untuk mendapatkan model matematis untuk kalibrasi sensor gas ke satuan part per million (ppm) dengan error 7,25\%.Sensor MQ-7 mampu mendeteksi gas berupa polutan karbon monoksida (CO) dengan error 9,4\% dibandingkan CO-meter. Saat quadcopter berada di ground terdapat selisih error pembacaan sensor gas MQ-7 dengan CO-meter di ground sebesar $\pm 0,5-3 \mathrm{ppm}$. Besar kecilnya polutan mempengaruhi pengukuran gas $\mathrm{CO}$ di quadcopter.

Dari hasil pengujian waypoint, didapatkan hasil error waypoint GPS sebesar 20-66 cm. Untuk pembacaan ketinggian quadcopter, bila dibandingkan dengan data sensor barometer, terdapat error rata-rata ketinggian sebesar $18,575 \%$. Hal ini diakibatkan kencangnya angin saat mode loiter.

Plotly berupa web server raspberry pi 2 mampu menampilkan data kadar gas ppm secara online real time. Hasil dari pemetaan gas polutan disajikan dalam model 3D analyzer google earth sehingga data gas dan posisi GPS dapat dipetakan.

\section{DAFTAR PUSTAKA}

[1] Purwitaningsih, Santika, "Polusi Udara dan Kaitannya dengan konomi Kota Surabaya", Surabaya, 2015.

[2] Neumann, Patrick P, "Gas Source Localization and Gas Distribution Mapping with a Micro-Drone", BAM Bundesanstalt für Material for schung und -prüfung, Berlin, 2013.

[3] Panjaitan Berkat, Siringo-Ringo Berliana, dkk, "Sensor Gas", Medan: Technology Science, Medan, 2013.

[4] Arya Adi Saputra dan Andi Dharmawan, "Rancang Bangun Quadcopter untuk Pemantauan Kadar Karbon Monoksida di Udara", UGM, Yogyakarta, 2013.

[5] Rengrajan, M., "Algorithm Development and Testing of Lowcost Waypoint Navigation System", Proceding of IRACST, Pune, India, 2013

[6] 3Drobotics, "Pixhawk Manual rev 7", <URL: http://3drobotics.com/ wp-content/uploads/ 2014/03/ pixhawk-manual-rev7.pdf>, 2014.

[7] ST-Electronics, "STM32F4 Discovery" <URL: http://www.st.com/web/catalog/tools/FM116/SC959/SS1532/PF252252 $>, 2015$. 